Stream: Culture/Politics/Technology, 6(1): 3-8

http://journals.sfu.ca/cpt/index.php/stream/index

\title{
Dialogue on Public Broadcasting in Canada: An Interview with Wade Rowland
}

Mike Mowbray

School of Communication, Simon Fraser University

Wade Rowland

Department of Communication Studies, York University

\section{Introduction}

In framing the call-for-papers that kicked off this special issue, we asked potential contributors: "what considerations might guide our attention as we think through public media as a socially central symbolic space that ought to be returned to the public interest? How might we come to reinhabit public institutions?" Further to this, we queried possible contributors about the role and potentials of public broadcasting (notably the CBC) in a changing mediascape, and the possibilities for public media - not limited to the specific domains of established public broadcasters such as the $\mathrm{CBC}$ and the provincial educational networks, but rather appealing to an open interpretation of the term - that might be prefigured or imagined at present. As outlined in the introduction to this issue, the written pieces that arose from this line of questioning are varied and vital in their contributions.

To place this exercise in context, it is important to note that this special issue of Stream was conceived and produced in conjunction with a public event held at the Wosk Centre for Dialogue at Simon Fraser University on February $6^{\text {th }}, 2014$ under the title 'Occupy Public Broadcasting: Alt Futures for the $\mathrm{CBC}^{\prime}$. That evening's discussion brought together an eclectic panel and participating audience of media scholars, practitioners, activists, and concerned community members in dialogue and debate over the relative merits, limitations, and - most importantly - the future prospects for the CBC, other public broadcasters, and public media beyond this (circumscribed) context.

We highly recommend that interested readers take the time to watch the video recording of the event (itself an excellent springboard for further conversations and for teaching), which can be viewed at http://i.sfu.ca/jrMeLE. These lively presentations and the dialogue of which they are a part stand on their own two feet, but also stand alongside the written contributions included in this special issue of Stream.

In the context of that evening's discussion, a number of distinct questions and contentions took shape (arising from both common and differing, sometimes incompatible, assumptions and priorities): how might a more robust public media system be sustained - perhaps by appropriating the tax subsidy already devoted to private networks in Canada? How to circumvent the potential barriers posed by national political actors openly hostile to public broadcasting, and by anti-tax ideology? Is the real question a matter of funding, or of governance and mandate? What is to be the impact of the recent Rogers deal that will see an end to Hockey Night in Canada, longtime anchor of CBC's programming schedule in terms both of ratings and ad revenues (a deal one participant described as "a grenade with a four-year fuse")? How is a public broadcaster to live up to ideals implying an educative function and a role in diffusion of high-culture content without becoming the province of an elite? What limits and possibilities arise from the particular 'technological imaginaries' of our public broadcasters? How can visioning and policy processes be animated not just by the rigidly constrained structures of extant bureaucratic entities, but opened up to broad public participation and enlivened by an appeal to the vitality of social movements? How are 'traditional' actors to respond to the advance of unregulated broadcast markets tied to networked computing? Is there even a continuing role for a national public broadcaster in an era of multiplatform proliferation of channels/outlets and of 'fragmented' audiences? 
These questions are too many, and too complex, to unpack here - but all are deserving of attention. It is our hope that this special issue of Stream helps to direct attention towards these and a universe of related questions. For the moment though, as a supplement to the dialogue captured in the video recording linked above, we wish to present an interview with Wade Rowland - a prominent figure in recent discussions specifically surrounding the possible fates of Canada's national public broadcaster who was originally slated to speak at that event. The editors of Stream caught up with Dr. Wade Rowland about six weeks after the February 2014 event - and while events have almost appeared to overtake us since, the content of the interview remains timely.

Rowland's recent work, addressing the acute dilemmas which face the CBC and outlining possible directions forward, animated a significant portion of the discussion at the 'Occupy Public Broadcasting' event - serving as a common point of reference for several speakers. In his 2013 book, Saving the CBC: Balancing Profit and Public Service, Rowland predicted that the corporation was no more than a year or two away from the point at which cuts to the public broadcaster's funding (which have been steep of late, and exacerbated by other revenue shortfalls) "will no longer lead to quantitative tinkering with its output, but to fundamental, qualitative transformation in the organization itself." Recent events would appear to cast such a prediction as prescient. Talk of shedding 1500 employees by 2020, of completely disbanding in-house documentary production, scaling back evening news (cutting local stations' broadcasts to 30 or 60 minutes from 90), dropping flagship programming priorities (e.g. filling the slot left open with the wind-down of 'Tonight' with existing dramas rather than developing another talk-and-current-events program in its place), of prioritizing digital and mobile delivery over television and radio - all seem to indicate a watershed moment. ${ }^{1}$

Of the specific suggestions outlined in Rowland's book, the notion that the CBC ought not to compete for broadcast rights for professional sport has caught on - of stark necessity, perhaps - but other components of the vision he forwards have not fared so well. When Sally Catto, CBC's new general manager of programming, disingenuously insists that "documentaries will be crucial" for a revamped CBC at the same time that it is announced that all production in the genre is to be farmed out in future rather than produced in-house, and when one of the most valuable contributions of the national public broadcaster, providing ample and authoritative local news through regional stations, is on the chopping block in most markets as well, it's hard to imagine that any advocate of 'quality news' and factual programming that speaks to national debates and to local particularities as a core mandate for public broadcasting could be anything but gravely concerned. ${ }^{2}$

In order to supplement the conversations captured in the video recording of the 'Occupy Public Broadcasting' event by bringing in a voice originally slated to deliver the keynote to that evening, Stream's editors put a few questions to Dr. Rowland, related to his recent work in advocating a particular vision, and a particular set of possible solutions, for the national public broadcaster.

\section{CBC and Public Media}

Kicking off our conversation, Stream editors called upon Rowland to comment on how his recent writing tends to defend the utility and value of the CBC (in its various channels) as a broadcaster - a constitutive of a symbolic 'centrality' in social (and national) terms, bringing together substantial audiences to engage in common viewing and listening experiences - at a time when some argue that 'broadcasting' itself is a passé notion. To quote event panelist Rebecca Sullivan, who argued

\footnotetext{
${ }^{1}$ http://www.cbc.ca/news/canada/cbc-to-cut-back-supper-hour-news-in-house-productions-1.2688409

- http://www.friends.ca/press-release/12179

2 http://www.theglobeandmail.com/arts/television/whats-next-for-a-leaner-cbc-without-hockey-we-askthe-new-head-of-tv-programming/article19088559/\#dashboard/follows/
} 
Stream: Culture/Politics/Technology, 6(1): 3-8

http://journals.sfu.ca/cpt/index.php/stream/index

that the $\mathrm{CBC}$ cannot be all things to all people, and shouldn't bother trying: "I don't think broadcasting is our future, I believe it is our past". Along these lines, we asked Dr. Rowland how he might respond to those who would argue that broadcasting as such belongs to a bygone era, and that a public broadcaster on the model of the CBC is ill-equipped to act in an environment characterized by an abundant proliferation of channels, platforms, sites to suit all tastes, cultural inclinations and allegiances, political perspectives and schedules?

In response, Rowland offered the following:

In my lexicon, "broadcaster" is simply a term of convenience. Of course, no public broadcaster these days limits itself to over-the-air radio and television, or even to cable and satellite distribution. They all have elaborate websites, which both supplement and augment their traditional offerings, and this is undoubtedly a large part of the future for public service media. Nevertheless, research shows that, for the moment, a remarkably persistent majority of us prefers to get our media on traditional appliances-radios and television sets-as opposed to smartphones, tablets, laptops, and other mobile devices.

This will undoubtedly change over time, but for the foreseeable future, broadcasting in the traditional sense will remain important.

To suggest that an established public broadcaster is somehow "ill-equipped" to take part in the on-line evolution of public service media is to forget that there is and will always be a need for authoritative, responsible, high-quality content on these new distribution platforms, and the provision of that kind of content remains the raison d'être of public service media organizations like the $C B C$ and $B B C$.

To respond to the argument that "The CBC cannot be all things to all people," I can do no better than to quote media scholar Michael Tracey, who says:

"Public broadcasting does not expect that it can please all of the people all of the timeindeed it sees in that approach precisely the kind of populism which nurtures cultural mediocrity, as quality is sacrificed on the altar of maximizing audience size. Public broadcasting does however believe that well-produced programs can please a lot of the people a lot of the time, and everybody some of the time. Public broadcasting is thus driven by the desire to make good programs popular and popular programs good...".

Further to this, we asked Rowland, as someone who has stepped unapologetically to the centre of the debate in this country, about his sense of the prevailing balance of forces and opinions, both in the public at large and amongst those political actors who might be positioned (now or after a federal general election) to enact changes along the line he suggests ought to be made to the mandate of the $\mathrm{CBC}$, the volume and sources of its Parliamentary appropriation, and the Board of Directors selection process. Given our own impression that the political will to do these things is not endemic amongst all the parties of Ottawa, we queried Dr. Rowland about what needs to happen to facilitate a vigorous popular movement in support of public broadcasting reform in Canada, and how he envisions the process of delivering change.

As far as I can see, there is no "debate" in this country over the CBC. Polling over the years has shown a large and consistent majority of Canadians support the public broadcaster, and that support transcends party lines. My intent has been to help to start such a debate, before it's too late. I have argued that the current financial crisis at the corporation is definitive, in the sense that the CBC will either emerge reorganized and newly dedicated to the purposes of public service, or it will vanish in any recognizable form.

It's unfortunate that none of the political parties has a well-developed policy addressing the $C B C$ 's moment of truth. The only thing that can put the CBC on the front burner for the parties is pressure from the public in all the traditional forms from letter writing to buttonhole their MPs 
at public events. The parties will take an interest if and when they can be convinced that there are votes to be gained by adopting a pro-CBC policy. The strategy I've outlined, while it is based on the historic foundations of public service broadcasting, happens to have elements that have appeal across the political spectrum.

What I have suggested is that the private broadcasting industry should be essentially deregulated (applause from the right!), and freed from requirements to produce and broadcast prescribed amounts of Canadian content. On radio, certainly, the enormous success of the initial can-con regulations has made their continuance unnecessary. On television, what passes for Canadian content is almost entirely characterized by cookie-cutter predictability overlaid by regional tokenism. We can hardly do worse, and I suspect that Canadian television broadcasters will discover that it is in their financial interest to continue to produce Canadian content whether it's required by the CRTC or not.

of course, once the regulatory requirements are eliminated, there will be no further need to subsidize private broadcasters through the various federal agencies that currently steer hundreds of millions of dollars their way each year. That money should be reallocated to the public broadcaster, where it belongs, and where one may presume that it will support superior programming. (Applause from the left!)

I have also argued that it is essential that CBC get out of the advertising business, across all its platforms. The reasons for this are many, but two stand out. First, a pubic broadcaster cannot serve both the public interest and its advertisers' interests simultaneously. CBC television, now replete with product placement and infomercials masquerading as "factual entertainment" (reality TV), has provided conclusive and irrefutable proof of this. On the other hand, Radio One, ad-free since 1971, demonstrates what happens to the quality of public service when commercial sponsorship goes away.

Second, using commercial revenue to supplement the Parliamentary appropriation has proved to be a slippery slope. As successive governments have sliced away at the CBC's subsidy, the corporation has sought relief in expanded advertising revenue. Each time that happens, the corporation is driven further into the embrace of advertisers, and the government of the day is let off the hook politically because the institution survives, if only on life-support.

The commercial broadcasting industry in this country has complained since the 1920s that it is unfair to force them to compete with a state-subsidized CBC for a finite pool of advertising dollars. This argument has gained substantial weight as CBC television programming has deliberately been steered into the established format territory of commercial broadcasters, notably under the stewardship of former VP English language programming, Richard Stursberg. Public and private televisions are providing essentially the same product, but the CBC is able to undercut its competitors thanks to its state subsidy.

This iniquitous situation will end when $C B C$ disavows advertising. And private broadcasters will reap the windfall of newly available advertising dollars. (Applause from the left and right!) I leave it to the specialists within the Department of Finance, the Department of Canadian Heritage, and the CRTC to work out an equitable formula for re-financing the CBC from newly freed-up subsidies, taxation on increased ad revenues, and perhaps a small public service levy (a Doyle tax) on the enormous profits of program distribution enterprises like Bell and Rogers. My considered opinion is that we could boost the CBC subsidy from he current $\$ 1$ billon to $\$ 2.5$ billion (lifting it from the basement to near the average PSB funding levels of OECD nations) without imposing a significant, or even noticeable, burden on any of the industry stakeholders, including audiences. The money needed to give Canada an adequately funded public broadcasting service exists within the system as it stands; what's needed is a thoughtful and equitable redistribution. 
Stream: Culture/Politics/Technology, 6(1): 3-8

http://journals.sfu.ca/cpt/index.php/stream/index

The argument in favor of a public broadcaster (or a public media organization) is especially strong with reference to the field of journalism, where news-gathering and investigative activities, not to mention adequate coverage of national, regional, and local events (both quotidian and exceptional) require organizational and financial resources that commercial newsrooms appear increasingly unwilling to furnish, and which alternative projects cannot effectively muster. Quality news, according to OpenMedia's 'Reimagine the CBC' project (as presented by Reilly Yeo at the 'Occupy Public Broadcasting' event, linked above, is among the highest priorities Canadians articulate for their public broadcaster. Yet it is news also (alongside some documentary programming) that seems to generate the greatest animus from opponents of public media on the right of the political spectrum (for example: Harper strategists in 2010 citing an "ongoing campaign against the Conservative Party" on the part of the corporation, echoing statements one might recall from Reform Party candidates in 1990s Saskatchewan). We asked Rowland his thoughts on this matter, and about how we might respond to the contention that a substantial portion of the Canada's population - i.e. those ensconced in a right-wing populist position promoted by the party currently running the federal government - believes the national broadcaster to be slanted against its priorities, its values, its candidates?

First of all, I can't agree that "a substantial portion of Canada's population" understand CBC to be biased in this way. Reputable polling data does not support this contention. To the degree that this view exists, it is promoted and amplified by vested financial interests whose objections to the continued existence of the CBC would largely disappear under the reorganization I am proposing.

"Quality in news," as you suggest, ought to be the highest priority for the CBC. Right now, that goal is continuously undermined by the competing and often incompatible goal of maximizing audiences in order to increase advertising revenue. The current strategy at the corporation mistakenly assumes that to compete with commercial broadcasters requires the $C B C$ to be as much like them as possible. Hence the spectacularly ill-conceived hiring of the American news doctors, Frank Magid and Associates, to tweak the look and feel of the CBC's news productions.

There will never be unanimous agreement as to what a "quality" newscast ought to look or sound like, either among audience members or media professionals. But a public broadcaster freed from the tyranny of overnight ratings would be able to experiment with competing concepts of quality. I strongly suspect it would end up looking a lot like BBC or ITN news, and that it would be at least as popular as the current product.

In 'Saving the CBC', Rowland suggests that the structure and regulation of the media industries (as well as the content they produce) are revealing of "a society's values and aspirations" (9) - and on the last page of the book (116), he places the prospect of a fully commodified mediascape alongside a list of other public goods and institutions (from roads to fine art museums) that readers might presumably wish to save from such a fate. Notions like "consumer sovereignty" (37), which serve the purposes of the commercial networks by working to legitimate priorities which do not rank "quality" as among the most pressing concerns, along with aspirations to minimalist government and accusations of bias against the corporation (as referenced above), underpin attacks on the CBC. And commentators such as Jay Scherer (e.g. at the February 6th event here in Vancouver) quite reasonably draw attention to the barriers that anti-tax ideology might pose to any alternative funding models for the $\mathrm{CBC}$, even when well-considered means are proposed: e.g. drawing away existing, and outmoded, subsidies to private broadcasters. What does all of this say, we asked, about our society's "values and aspirations"? To what extent is the struggle over the CBC as emblematic of a broader political, social, and cultural battle? 
I hope I have addressed the issue of the "anti-tax" lobby and free market ideals above: once the private industry is unleashed to do its thing, very little, if any "new money" will be needed to properly fund the CBC. Even rock-ribbed libertarian economists recognize the inevitability of occasional "market failures" and the existence of "merit goods," and the need to make allowance for each of these through publicly financed institutions. The CBC's output is both a merit good and necessary compensation for an obvious free-market failure, hence a legitimate object of government subsidy (as is, for example, the public school system).

The issue of atomization of audiences both as a by-product of new technology and as a response to the philosophy of possessive individualism is an undeniable concern. A broadcast audience is, as Richard Nielsen has observed, a "congregation," and a large part of the traditional role of public broadcasting in this country has been to regularly assemble that congregation in order to inform, enlighten, and entertain it in the context of goals, values, and aspirations we take to be emblematic of liberal democracy, Canadian style.

As assembling such a congregation becomes more difficult in coming decades, some alternative means of "public sphere" communication will have to be developed if we are to avoid a descent into the kind of narcissistic, techno-punk abyss in which the tyranny of convenience triumphs over the Socratic good life. How to do that is an issue that needs to be taken up by academic research, and explored by media practitioners. But whatever it may turn out to be, it is clear that public service media-should they remain a feature of the brave new world-will be part of the solution, not part of the problem.

\footnotetext{
About the Authors

Mike Mowbray is co-managing editor of Stream and PHD Candidate at School of Communication, Simon Fraser University. His dissertation project focuses on the representation of urban struggles in Vancouver's Georgia Straight newspaper, the genre shift from 'underground' to 'alternative weekly' press, and the transformations of the physical, political, social, and cultural landscapes of the central city from the 1960s to present.

Wade Rowland is an Assistant Professor in the Department of Communication Studies at York University. He is also one of Canada's leading literary non-fiction authors. Author of Greed Inc., Galileo's Mistake; Ockham's Razor; and Spirit of the Web. He is a long-time journalist who has worked for the Winnipeg Free Press, the Toronto Telegram and both national Canadian television networks: CBC (Canadian Broadcasting Corporation) and the CTV Television Network.
} 